Diabetologia 10, 201-204 (1974)

(C) by Springer-Verlag 1974

\title{
Control of Diabetes: An Attempt to Formulate Policy Guidelines in a Department of Medicine
}

\author{
P. Lefèbvre, J. Milet and A. Luyckx* \\ Division of Diabetes, Institute of Medicine, University of Liège, Belgium \\ Received: October 15, 1973, and in revised form: February 7, 1974
}

\begin{abstract}
Summary. Three hundred and twenty eight serial measurements of blood glucose (SMBG) performed in a Department of Medicine were rated by 7 experienced diabetes specialists. A statistical study showed considerable variation among the raters. Similarly, the ratings of the 7 physicians relative to the mean rating showed a great deal of individual variation. A highly satisfactory correlation was found between the mean rating of the 7 physicians and the M-value of Schlichtkrull as computed from 7 or 8 samples collected during the day. On the basis
\end{abstract}

of these findings the degree of diabetes control for this population can be judged satisfactory, good or very good when the M-value is $\leqslant 10$. If the M-value is $\geqslant 22$, control is poor or very poor and major changes in the treatment program are indicated. Intermediate values, seen in one out of five cases, indicate the need for systematic consultation with a diabetes specialist.

Key words: Diabetes, control, M-value, blood glucose, computer.
It is widely accepted at present that diabetes mellitus is a disease involving much more than the metabolism of ghucose per se. Nevertheless, most specialists agree that measurement of blood or urine glucose levels remains the simplest method of judging the degree of diabetes control. The criteria for judging the degree of control are controversial. However most authors $[1,3]$ with the exception of Knowles [6], concede that "good metabolic control" lowers the incidence of long-term complications. Many diabetologists request that their patients check their urine for glucose several times daily. The patients are counselled to evaluate glycosuria quantitatively if positive results are obtained. This method is far from ideal. The absence of sugar in the urine means only that the blood glucose level has not exceeded the renal threshold for glucose, which is usually between 160 and $180 \mathrm{mg} \%$. During hypoglycemia no glucose will be found in the urine, by definition. It should be mentioned that many patients have renal thresholds for glucose which are abnormally high or low. In the case of abnormally high thresholds, the absence of glycosuria will result in the diabetes being erroneously considered as well controlled. In the presence of an abnormally low threshold, glucose will be found in the urine of patients with well-controlled diabetes. In practice, however, having the patient check his urine for glucose several times a day is of great value in verifying the degree of control once the renal threshold for glucose has been determined. Serial measurements of blood glucose (SMBG) make possible more accurate determination of diabetic control. These measures are usually performed on hospitalized patients and in circumstances differing from the usual home environment. We have found values to vary when they were obtained in hospitalized patients as compared with

* Chargé de Recherches du Fonds National de la Recherche scientifique (Belgium). patients in home or work situations (unpublished observations). The frequency and scheduling of sampling impose a constant constraint on the system, whatever method is used in obtaining SMBG. Several authors have emphasized the value of continuous blood glucose analysis $[4,7,8,9]$. Ideally blood glucose levels should be recorded continuously under ordinary living conditions. Present-day technology offers little hope of attaining this objective in the near future, especially on a large scale. Nevertheless, SMBG performed on hospitalized patients are widely used (see review in 2), although the criteria used for judging the regulation of diabetes vary between departments and even within departments. The opinions of specialists can differ greatly as a function of such variables as experience and individual psychology.

We have attempted to compare the ratings of several physicians experienced in Diabetology on a group of SMBG performed on diabetic patients hospitalized at the Institute of Medicine of the University of Liège. In the second phase of this study we compared the average rating of these specialists with a quantitative estimate of diabetic control, the M-value of Schlichtkrull et al. $[10,11]$.

\section{Material and Methods}

1. $328 \mathrm{SMBG}$ performed over a period of 14 months were used. Each consisted of $7-8$ samples taken over a $24 \mathrm{~h}$ period in diabetic patients. Some patients were hospitalized for several days while others only remained in the hospital for the test period. The follow. ing sampling schedule was followed in most cases: fasting (8 A.M.), 11/2 h after breakfast, before lunch (noon), $2 \mathrm{~h}$ after lunch, before dinner (6 P.M.), $2 \mathrm{~h}$ after dinner and at 10 P.M. or midnight. In some cases samples were taken every $3 \mathrm{~h}$. 
2. Venous blood was collected in heparin-rinsed syringes and transferred to tubes containing a trace of sodium fluoride. All tubes of a single patient were kept at $+4^{\circ} \mathrm{C}$ until the completion of the sampling and blood glucose was determined simultaneously for all samples on the next morning. Blood glucose was measured by the method of Hoffman [5], adapted to the Technicon Auto-Analyzer. In the normal fasting subject, mean blood glucose was $74 \pm 4 \mathrm{mg} \%$ and the postprandial concentration did not exceed $120-$ $140 \mathrm{mg} \%$.

3. A set of $328 \mathrm{SMBG}$ was submitted to 7 experienced diabetes specialists (internists with special training in endocrinology and diabetes, with experience in the treatment of diabetes ranging from 4 to 30 years $)^{1}$. Each physician was asked to rate independently the quality of diabetes control using the following scale: severe (lower score) or more tolerant (higher score) rating than the mean for all raters.

- Frequency with which rating categories were selected by each physician

- Mean global rating (sum of scores divided by 328) for each physician considered separately.

6 . The average rating of the 7 physicians for each SMBG considered separately was compared with the value of $\mathbf{M}$ as calculated above.

\section{Results}

\section{Statistical Distribution of the Ratings of the 7 Diabetes Specialists}

Table 1 shows the number of ratings in each category assigned by each physician. It will be noted that the ratings for a given SMBG show considerable varia-

Table 1. Distribution of 328 SMBG into 5 categories by 7 diabetes specialists

\begin{tabular}{ccccll}
\hline & $\begin{array}{c}\text { Rating 1 } \\
\text { Very poor }\end{array}$ & $\begin{array}{l}\text { Rating 2 } \\
\text { Poor }\end{array}$ & $\begin{array}{l}\text { Rating 3 } \\
\text { Satisfactory }\end{array}$ & $\begin{array}{l}\text { Rating 4 } \\
\text { Good }\end{array}$ & $\begin{array}{l}\text { Rating 5 } \\
\text { Very good }\end{array}$ \\
\hline Physician A & 65 & 55 & 105 & 66 & 37 \\
B & $\mathbf{1 0 3}$ & 105 & 53 & 26 & 41 \\
C & 29 & 104 & 128 & 49 & 18 \\
D & 71 & 72 & 56 & 55 & 74 \\
E & 85 & 68 & 60 & 52 & 63 \\
F & 24 & 55 & 104 & 63 & 82 \\
G & 76 & 92 & 110 & 45 & 1 \\
\hline
\end{tabular}

a Physician G did not rate 4 SMBG in the series of 328 .

- Very poor control: 1

- Poor control: 2

- Satisfactory control: 3

- Good control: 4

- Very good control: 5

The physicians were deliberately requested to rate on the basis of the quantitative data alone without using any clinical information.

4. The M-value of Schlichtkrull was calculated for the 328 SMBG using the IBM 1800 computer of the Computing Center of the University of Liège. The formula used was

$$
M=\frac{1}{n} \cdot \sum_{i=1}^{i=n}\left[10 . \log \frac{B S_{i}}{120}\right]^{3}+\frac{1}{20} \cdot W
$$

where $B S$ represents blood glucose in $\mathrm{mg} \%, W$ the difference between the lowest and highest blood glucose values, and $n$ the number of determinations.

5. A statistical study of the ratings was performed and the following parameters were calculated:

- Rating variability as measured by sigma values

- Frequency with which each physician gave a more

1 We gratefully acknowledge the assistance of Drs. Brakier, Daubresse, Hamoir, Hennen and Margoulies who assisted two of the authors (P. Lefebvre and A. Luyckx) in rating the $\mathrm{SMBG}$. tion. For example, physician G considered control to be excellent only once while physician F throught control to be excellent 82 times. Inversely, control was considered very poor only 24 times by physician $\mathrm{F}$, whereas this rating was assigned 103 times by physician B.

\section{Statistical Analysis of the Individual Ratings Relative to the Mean Rating}

The frequency with which each physician gave ratings differing from the mean by more than one standard deviation has been calculated. It was $34 \%$ for physician $\mathrm{A}, 38 \%$ for $\mathrm{B}, 15 \%$ for $\mathrm{C}, 17 \%$ for $\mathrm{D}$, $22 \%$ for $\mathrm{E}, 42 \%$ for $\mathrm{F}$ and $30 \%$ for $\mathrm{G}$.

\section{Mean Rating of Each Physician}

The mean rating for each physician on individual SMBG was calculated. This parameter gives a quantitative measure of the degree of "strictness" or "tolerance" of each rater. The mean rating was 2.86 for physician A; 2.3 for B; 2.76 for C; 2.96 for D; 2.81 for $\mathrm{E} ; 3.37$ for $\mathrm{F}$ and 2.39 for $\mathrm{G}$. This indicates that, on the average, the most tolerant ratings were made by physician $\mathrm{F}$ and the more severe by physician $\mathrm{B}$.

\section{Comparison of the Mean Ratings of the 7 Physicians with the $M$-Values}

Fig. 1 is a plot of the mean rating of each SMBG (ordinate) versus the M-value of Schlichtkrull. For 
values of $\mathrm{M} \leqslant 10$ the mean rating is good, very good or excellent in 130 of 133 cases. For values of $M \geqslant 22$, the mean rating is poor or very poor in 125 of 127 cases. When $\mathrm{M}$ is less than 22 and greater than 10 the mean ratings are divided. This latter situation occurred in 68 cases $(20.3 \%)$. b) Relatively liberal raters

c) Physicians distributing their ratings in a relatively homogenous fashion across the categories.

This is confirmed by the fact that physician $\mathrm{F}$ for example, considered liberal from the data of Table 1 , assigned a more liberal (or optimistic) rating than the

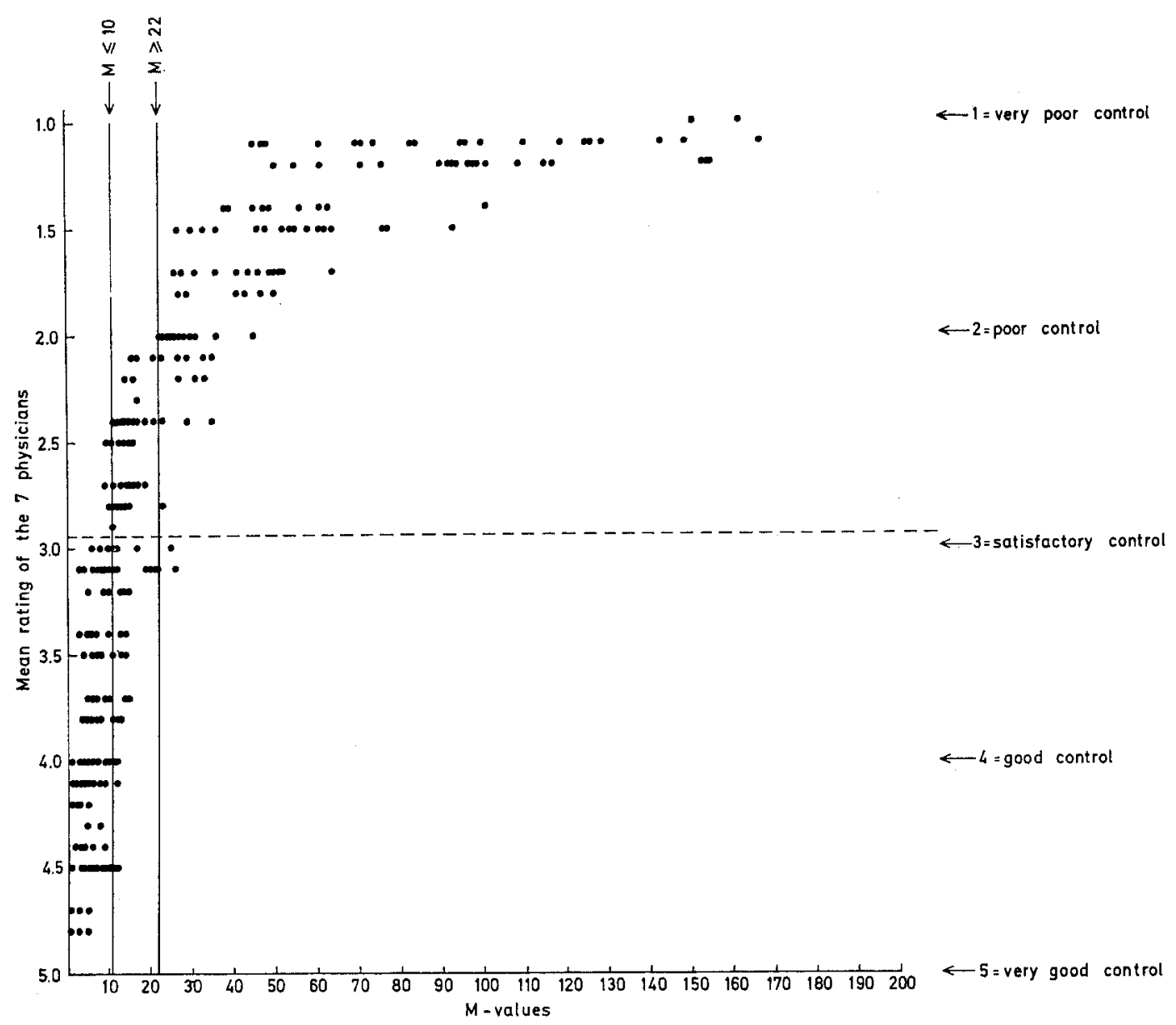

Fig. 1. Relation between mean ratings of the 7 physicians (ordinate) and M-values (abcissa)

\section{Discussion}

In the Introduction to this paper we emphasized the difficulties inherent in the techniques used to judge diabetes control. The measurement of blood glucose at different times of the day is generally conceded to be of value, independent of other metabolic parameters. These measurements are of even greater value when the samples are taken under the patient's usual living conditions. This study demonstrates that estimates of diabetes control vary greatly among physicians even when many blood glucose samples are obtained in a single day. On the basis of the ratings given, three groups of physicians can be distinguished:

a) Strict raters who rarely considered the diabetes to be well or very well regulated. mean 140 out of 328 times. Similarly physician B, who was considered very strict on the basis of the data of Table 1, assigned more severe (or pessimistic) ratings than the mean 105 out of 328 times. It is difficult to make the virtually philosophic choice between these different orientations. We nevertheless consider that the mean rating of the 7 physicians for each SMBG is a valid parameter. Supporting this view is the highly satisfactory correlation found in most cases between the mean rating and Schlichtkrull's M-values. We consider the M-value to be a particularly valuable parameter in judging diabetic stability and the degree of control. In its first application the M-value was computed on the basis of 6 or 7 determinations daily for 6 to 8 consecutive days [10]. The M-value takes into consideration a number of characteristics which 
we believe to be essential: the absolute value of blood glucose, the severity of hypoglycemia, and the magnitude of fluctuations in blood glucose. Mirouze et al. [8] have recently confirmed the validity of the M-value on the basis of continuous blood glucose analysis, by recalculating the value from 24 measurements of blood glucose over a $24 \mathrm{~h}$ period. The present paper confirms the practical value of similar calculations even when made on the basis of only 8 determinations. Mirouze et al. [8] have admittedly established that M-values vary with the number of determinations performed. Nevertheless, these authors have shown that 24-25 daily determinations yield M-values whose precision is only slightly increased by any further increase in the number of determinations. It can scarcely be doubted that the optimal information is furnished by continuous blood glucose analysis. However, such a technique has the disadvantage of immobilizing the patient and thus placing him in conditions which may differ greatly from those of his daily life. It is our personal opinion that performing 7-8 determinations of blood glucose in a work and/or home environment such as we have done (unpublished observations) can provide useful information. In addition we consider that the systematic calculation of M-values from these blood glucose data can yield supplementary information of great value. As stated above, the mean rating of the 7 diabetes specialists under the study conditions was that $98 \%$ of patients had satisfactory, good or excellent regulation of their diabetes when the M-value was $\leqslant 10$. Control can be rated as increasingly good as M-values decline. Conversely, an M-value of $\geqslant 22$ indicates inadequate regulation, with control becoming increasingly poor with higher M-values. One can imagine these criteria being used to define rational treatment guidelines in a Department of Medicine: SMBG values yielding $M$-values $\leqslant 10$ would indicate regulation that was satisfactory or better. M-values $\geqslant 22$ would require changes in the parameters affecting diabetes, such as diet, exercise, insulin dose or oral hypoglycemic agents. The most difficult case is that presented by $\mathrm{M}$ values between 11 and 22 . In such cases systematic consultation with a diabetes specialist would be indicated. We plan a trial of this approach at the Institute of Medicine of the University of Liège.

Acknowledgements. We are indebted to Messrs Tibaux, Sabatier and Mayeres for their assistance in these studies and to Mrs. E. Vaessen-Petit for her expert secretarial assistance.

\section{References}

1. Allen, F.M.: A personal view of the therapy of diabetes mellitus. Diabetes 11, 336-338 (1962)

2. Aubertin, J.: Les critères de contrôle du diabète. In: Journées annuelles de Diabétologie de l'Hôtel-Dieu pp. 267-278. Paris: Flammarion 1972

3. Constam, G.R.: Contrôle du diabète et prévention des complications. In: Journées annuelles de Diabétolo. gie de l'Hôtel-Dieu, pp. 313-320. Paris: Flammarion 1972

4. Debry, G., Guisard, D., Mejean, L., Drouin, P.: L'enregistrement continu de la glycémie. Méthode d'étude en clinique humaine de l'activité hypoglycémiante des substances pharmacologiques. In: Journées Annuelles de Diabétologie de l'Hôtel-Dieu, pp. 303-311. Paris: Flammarion 1972

5. Hoffman, W.S.: A rapid photoelectric method for the determination of glucose in blood and urine. J. biol. Chem. 120, $51-55$ (1937)

6. Knowles, H.C., Jr.: Control of diabetes and the progression of vascular disease. In: Diabetes mellitus. Theory and practice, pp. 666-673. Ellenberg, M., Rifkin, H. (Eds.). New-York: Mc Graw Hill 1970

7. Mirouze, J., Satingher, A., Sany, C., Jaffiol, C.: Coefficient d'efficacité insulinique. Coefficient M de Schlichtkrull corrigé et simplifié par la technique de l'enregistrement glycémique continu. Le diabète $267-273(1963)$

8. Mirouze, J., Collard, F., Teisseire, J.P.: Intérêt de l'enregistrement glycémique continu dans l'analyse du diabète sucré insuliné. In: Journées annuelles de Diabétologie de l'Hôtel-Dieu, pp. 285-301. Paris: Flammarion 1972

9. Service, F.J., Molnar, G.D., Rosevear, J.W., Ackerman, E., Gratewood, L.C., Taylor, W.F.: Mean amplitude of glycemic excursions, a measure of diabetic instability. Diabetes 19, 644-655 (1970)

10. Schlichtkrull, J., Funder, J., Munck, O. : La confrontation des résultats cliniques en diabétologie. Evaluation d'une préparation elinique expérimentale. In: Journées annuelles de Diabétologie de l'Hôtel-Dieu, pp. 143-151. Paris: Flammarion 1961

11. Schlichtkrull, J., Munck, O., Jersild, M.: The M-value, an index of blood sugar control in diabetics. Acta med. scand. 177, 95-102 (1965)

Prof. P. Lefèbvre Institut de Médecine Hôpital de Bavière Bld. de la Constitution, 66 B-4000 Liège

Belgium 